\title{
ПРИМЕНЕНИЕ ИМИТАЦИОННОЙ МОДЕЛИ ЦЕПОЧКИ ПОСТАВОК СЫРОЙ НЕФТИ И НЕФТЕПРОДУКТОВ
}

\section{APPLICATION OF A SIMULATION MODEL OF A SUPPLY CHAIN OF CRUDE OIL AND PETROLEUM PRODUCTS}

\section{G. Azieva \\ A. Alimagambetova}

Summary. This article discusses the development of modern mathematical models of supply chains of crude oil and oil products to Kazakhstan for the scientific substantiation of the characteristics of the country's oil and gas industry. Supply chains consist of a structure of stocks and flows designed to acquire, store and retrieve incoming resources and translate them into decision rules governing flows. Supply chains consist of the structure of stocks and flows for the purchase, storage and release of incoming resources, and decision rules governing flows.

In addition, at present, the informational, economic and socio-political development of society is directly related to the culture of digital technologies. The desire for technological and structural reform in many countries, including Kazakhstan, prompts the state to make a number of decisions regarding the use of digital technologies in various spheres of population activity. The oil and gas industry in Kazakhstan is a key sector in its national economy, and it is envisaged that increasing the productivity of oil and gas fields through the use of digital technologies will increase Kazakhstan's competitiveness in the global economy.

To achieve this goal, the following tasks were considered:

a) analysis of the situation in the oil industry of the Republic of Kazakhstan;

b) evaluation of the characteristics of agents for the supply of crude oil and oil products based on computer experiments.

A managerial decision made on the basis of computer experiments to assess the characteristics of agents for the supply of crude oil and petroleum products can serve as an information base in the formation and development of clusters of the country's oil industry. By making decisions based on computer experiments in the field of supply chains of crude oil and petroleum products, using computer experiments on the supply of crude oil and petroleum products, we can achieve the ability to assess the performance of agents in the oil and gas industry of a country.

Keywords: simulation model, oil, supply chain, agent, storage, devices, mobile personnel.
Азиева Гульмира Тагибергеновна

Евразийский национальный университет

им. Л.Н. Гумилева

gulmira_azieva@mail.ru

Алимагамбетова Айнагуль Зейнетулловна

К.ф.-м.н., старший преподаватель, Казахский университет экономики, финансов и международной

торговли

ainash_777@mail.ru

Аннотация. В данной статье рассматривается разработка современных математических моделей цепочек поставок сырой нефти и нефтепродуктов в Казахстан для научного обоснования характеристик деятельности нефтегазовой отрасли страны. Цепочки поставок состоят из структуры запасов и потоков, предназначенных для приобретения, хранения и извлечения входящих ресурсов и преобразования их в правила принятия решений, регулирующие потоки. Цепочки поставок состоят из структуры запасов и потоков для покупки, хранения и выпуска входящих ресурсов и правил принятия решений, регулирующих потоки.

Кроме того, в настоящее время информационное, экономическое и социально-политическое развитие общества напрямую связано с культурой цифровых технологий. Стремление к технологическому и структурному реформированию во многих странах, в том числе и в Казахстане, побуждает государство принимать ряд решений, касающихся применения цифровых технологий в различных сферах деятельности населения. Нефтегазовая отрасль Казахстана является ключевым сектором в его национальной экономике, и предусмотрено, что повышение производительности нефтегазовых месторождений за счет применения цифровых технологий позволит повысить конкурентоспособность Казахстана в мировой экономике.

Для реализации данной цели были рассмотрены следующие задачи: а) анализ ситуации в нефтяной отрасли Республики Казахстан;

б) оценка характеристик агентов по поставке сырой нефти и нефтепродуктов на основе компьютерных экспериментов.

Управленческое решение, принятое на основе компьютерных экспериментов оценки характеристик агентов по поставке сырой нефти и нефтепродуктов, может служить информационной базой при формировании и развитии кластеров нефтяной отрасли страны. Принимая решения на основе компьютерных экспериментов в области цепочек поставок сырой нефти и нефтепродуктов, используя компьютерные эксперименты по поставке сырой нефти и нефтепродуктов, мы можем достичь возможности оценки характеристик деятельности агентов нефтегазовой отрасли страны.

Ключевые слова: имитационный модель, нефть, цепочка поставок, агент, хранилище, устройства, мобильный персонал. 


\section{Ввемение}

O дним из основных направлений прогресса в процессах добычи и транспорта сырой нефти и нефтепродуктов является развитие технологий компьютерного имитационного моделирования. Цепочки поставок состоят из структуры запасов и потоков для приобретения, хранения и преобразования вводимых ресурсов в выходы и правил принятия решений, регулирующих потоки. Цепь поставок транспорта сырой нефти и нефтепродуктов включает сети запаса и подачи материалов как сталь.

Сталь двигает от кренов металлического листа через штемпелевать в части тела к агрегату и пересылке к торговцам. На каждом этапе процесса имеется запас деталей, буферизующих различные виды деятельности. Структура решений, регулирующих потоки, включает в себя политику заказа стали у поставщиков, планирование штамповки кузовных деталей и сборки, доставку новых автомобилей дилерам и решение о покупке клиентов.

Исходя из особой значимости темы, целью данного исследования является разработка современных математических моделей цепочки поставок сырой нефти и нефтепродуктов в Казахстане для научного обоснования характеристик деятельности агентов нефтяной отрасли страны.

В соответствии с поставленной целью проектом предусматривается выполнение основных задач:

- дать анализ ситуации нефтяной отрасли Республики Казахстан;

- дать оценку параметрам характеристик агентов цепочки поставок сырой нефти и нефтепродуктов на основе компьютерных экспериментов.

Научной новизной проведенных исследований является:

- оценка параметров характеристик агентов цепочки поставок сырой нефти и нефтепродуктов;

- компьютерный эксперимент модели цепочки поставок нефти и нефтепродуктов в Республике Казахстан: Хранилище, Нефтеперерабатывающий завод, Трубопровод и Терминал нефтепродуктов.

Отметим, что полученными результатами научного исследования служат:

- овладение знаниями, умениями и навыками принятий решений на основе компьютерных экспериментов в области цепочки поставок сырой нефти и нефтепродуктов;

- практическое использование возможных и реалистичных оценок характеристик деятельности агентов нефтяной отрасли страны с помощью компьютерных экспериментов цепочки поставок сырой нефти и нефтепродуктов [1-6].

Для объяснения происхождения колебаний используется структура управления запасами. Колебания требуют, как временных задержек в негативных обратных связях, регулирующих состояние системы, так и того, чтобы лица, принимающие решения, не учитывали эти задержки, игнорируя линию подачи корректирующих действий, которые были инициированы, но еще не оказали своего воздействия. Хотя глупо игнорировать временные задержки, опыт показывает, что люди часто именно так и поступают. Тематические исследования различных отраслей показывают, что эти ошибочные представления о обратной связи лежат в основе постоянных циклов в недвижимости, судоходстве и смежных отраслях.

Одним из основных направлений научно-технического прогресса в процессах добычи и транспорта сырой нефти и нефтепродуктов является развитие технологий компьютерного имитационного моделирования. Все процессы отрицательной обратной связи включают в себя сравнение состояния системы с желаемым состоянием, а затем инициирование корректирующих действий для устранения любого несоответствия. В такие задачи управления запасами, менеджер стремится поддерживать запас (состояние системы) на определенном целевом уровне, или, по крайней мере в приемлемом диапазоне. Запасы изменяются только за счет изменения их притока и оттока. Как правило, менеджер должен установить скорость притока, чтобы компенсировать потери и использование и противодействовать возмущениям, которые отталкивают акции от желаемой стоимости. Часто между началом контрольного действия и его эффектом и между изменением запаса и восприятием этого изменения лицом, принимающим решение, возникают задержки. Продолжительность этих задержек может варьироваться и зависеть от действий самого человека.

Проблемы управления запасами возникают на многих уровнях агрегирования. На уровне фирмы менеджеры должны заказывать детали и сырье для поддержания запасов, достаточных для продолжения производства с требуемой скоростью. Они должны учитывать различия в использовании этих материалов и изменения в задержках их доставки. На индивидуальном уровне вы регулируете температуру воды в утреннем душе, ведете свой автомобиль по шоссе и управляете балансами своих чековых счетов [4].

Компьютерная имитационная модель цепочки поставок сырой нефти и нефтепродуктов будет построена на базе агент-ориентированной модели, которая состоит из следующих активных объектов: 


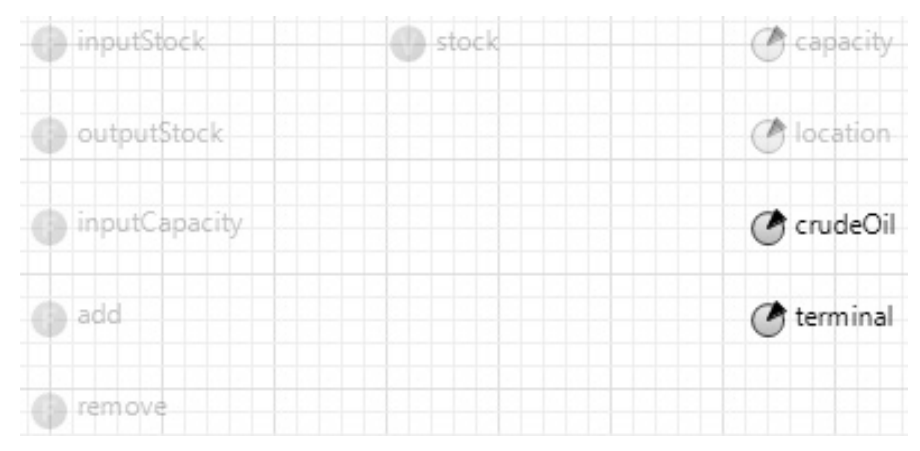

Рис. 1. Блок-схема модели агента Хранилища(Storage)

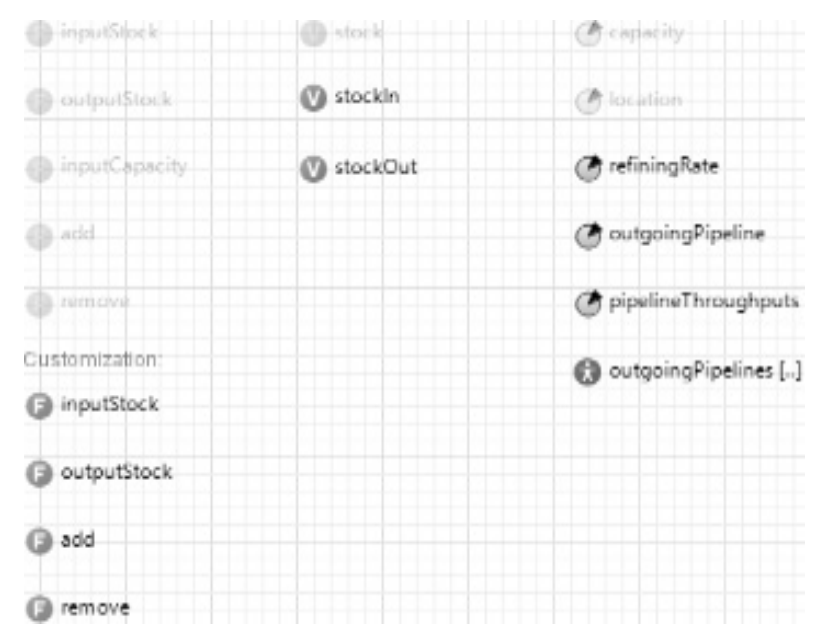

Рис. 2. Блок-схема модели агента НП3 (Refinery)

- Агент Хранилища сырой нефти ब, Storage (и/ или припортовые хранилища сырой нефти и/или нефти при месторождении), в котором активный объект Параметры используются для задания статических характеристик объекта, а ее значение остается неизменным во время «прогона» модели. Все параметры видны на презентации модели и обозначены в виде $($, а также можно изменять их значения во время работы модели либо программе из кода модели, либо с помощью элементов управления. В модели цепочки поставок нефти и нефтепродуктов для агента Хранилища сырой нефти используются два параметра-переменные (см. Рисунок 1).

- Сырая нефть 6 , crudeOil, Значение по умолчанию: false.

- Терминал $\mathcal{G}$, terminal, значение по умолчанию: false.

- Агент НПз ब, Refinery (нефтеперерабатывающий завод сырой нефти), в котором состоит из трех параметров-переменных (см. Рисунок 2).

- Норма переработки $\mathcal{G}$, refiningRate,
- Начало трубопровода $\odot$, outgoingPipeline,

- Пропускная способность трубопровода (), pipeline Throughputs, а также при разработке агента НПЗ используются Переменные (которые обозначены в виде (V) для моделирования изменяющихся характеристик активного объекта и/или для хранения результатов работы модели, в частности агент НПЗ состоит из двух переменных:

- Есть в наличии (запас) (V), stockln,

- Нет в наличии (запас) (V, stockOut, а также среда AnyLogic позволяет пользователям создавать свои собственные функции. С помощью функций можно единожды задать определенную последовательность действий (обычно - вычислений, возвращающих результат), которую нужно будет выполнять из разных мест (или в разные моменты жизни) модели [5].

Функции пишутся на языке Java, поэтому в распоряжении Пользователя имеются все преимущества этого языка, такие, как, например, условные операторы (if- 


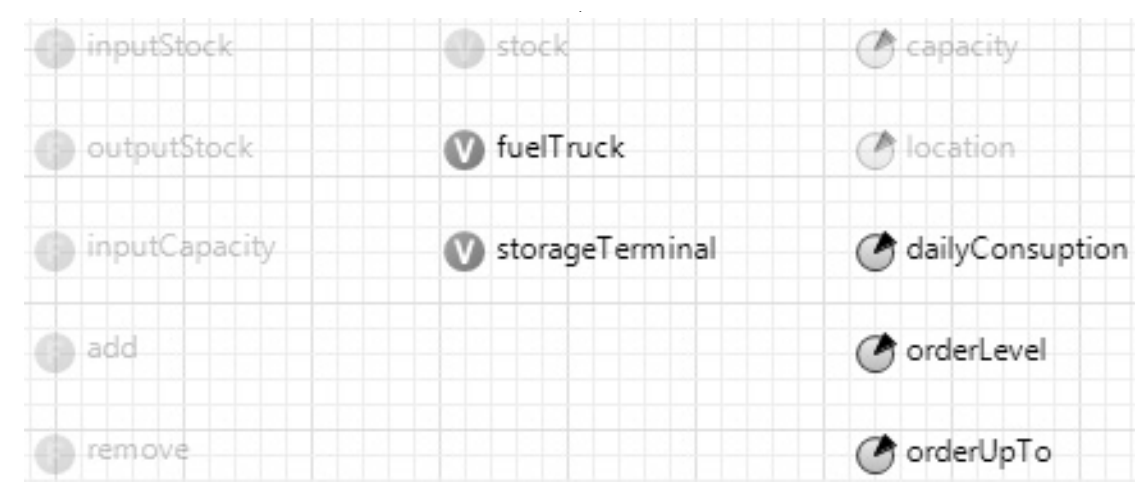

Рис. 3. Блок-схема модели агента Ритейлера (Retailer)

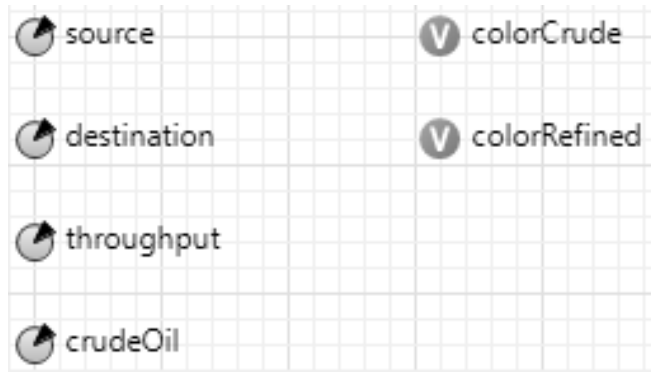

Рис. 4. Блок-схема модели агента Нефтепровод (Pipeline)

then-else), циклические операторы (while, for), операторы ветвления (switch) и т.д., в частности агент НПЗ состоит из четырех функции:

- Добавить $\mathrm{E}$, add, которая определяет действие: if(stockln + amount > capacity) error("Overflow: trying to add above capacity"); stockln += amount;

- Вход в запас $\mathrm{E}$, inputStock, которая возвращает значение: stockln;

- Выход их запаса E, outputStock, которая возвращает значение: stockOut;

- Удалить $\mathrm{E}$, remove, которая определяет действие:

if(stockOut - amount <0)

error("Trying to remove more than available"); stockOut-= amount;

- Агент Ритейлер нефтепродуктов $\boldsymbol{\theta}$, Retailer (ритейлер нефтепродуктов, розничная торговля нефтепродуктов), который состоит из трех параметров-переменных (см. Рисунок 3).

- Дневное потребление нефтепродуктов dailyConsuption, Значение по умолчанию:

- Уровень запроса на нефтепродукты orderLevel, Значение по умолчанию: 10

- Запрос на нефтепродукты до востребования , orderUpTo, Значение по умолчанию: 30, а также агент Ритейлер нефтепродуктов состоит из двух переменных:

- Бензовоз нефтепродуктов (V, fuelTruck, Начальное значение: main.fuel Trucks.get(getIndex()),

- Терминал-хранилище нефтепродуктов (V) storage Terminal.

- Агент Нефтепровод для транспортировки сырой нефти и нефтепродуктов $\boldsymbol{\theta}$, Pipeline (нефтепровод для транспортировки сырой нефти и нефтепродуктов), который состоит из трех параметров-переменных (см. Рисунок 4):

- Сырая нефть $\mathcal{F}$, crudeOil, Значение по умолчанию: false

- Пункт назначения для транспортировки сырой нефти и нефтепродуктов $\odot$, destination, Значение по умолчанию: false.

- Начало транспортировки сырой нефти и нефтепродуктов $\mathcal{O}$, source,

- Пропускная способность транспортировки для сырой нефти и нефтепродуктов $\mathcal{C}$, throughput, Значение по умолчанию: 10, а также агент транспортировки сырой нефти и нефтепродуктов состоит из двух переменных:

- Цвет сырой нефти V, colorCrude, Начальное значение: $\operatorname{Color}(64,64,64,230)$,

- Цвет нефтепродуктов $\mathbf{V}$, colorRefined, Начальное значение: Color(255, 165, 0, 210). 


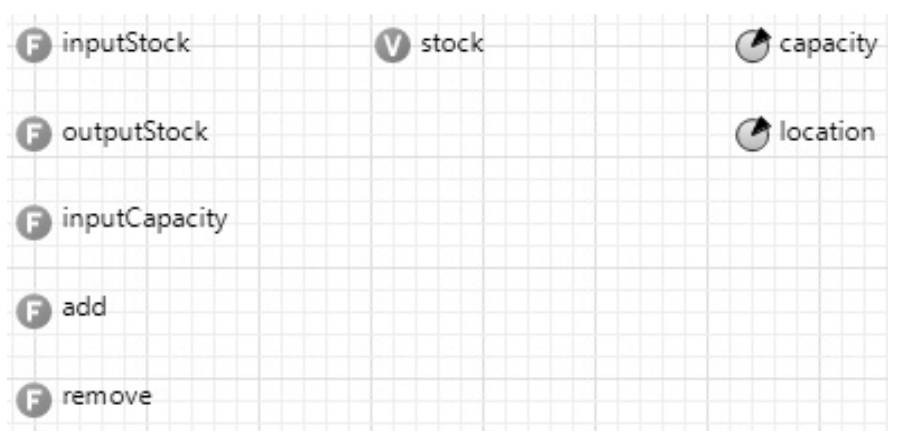

Рис. 5. Блок-схема модели агента Узлы Нефтепровода (PipelineNode)

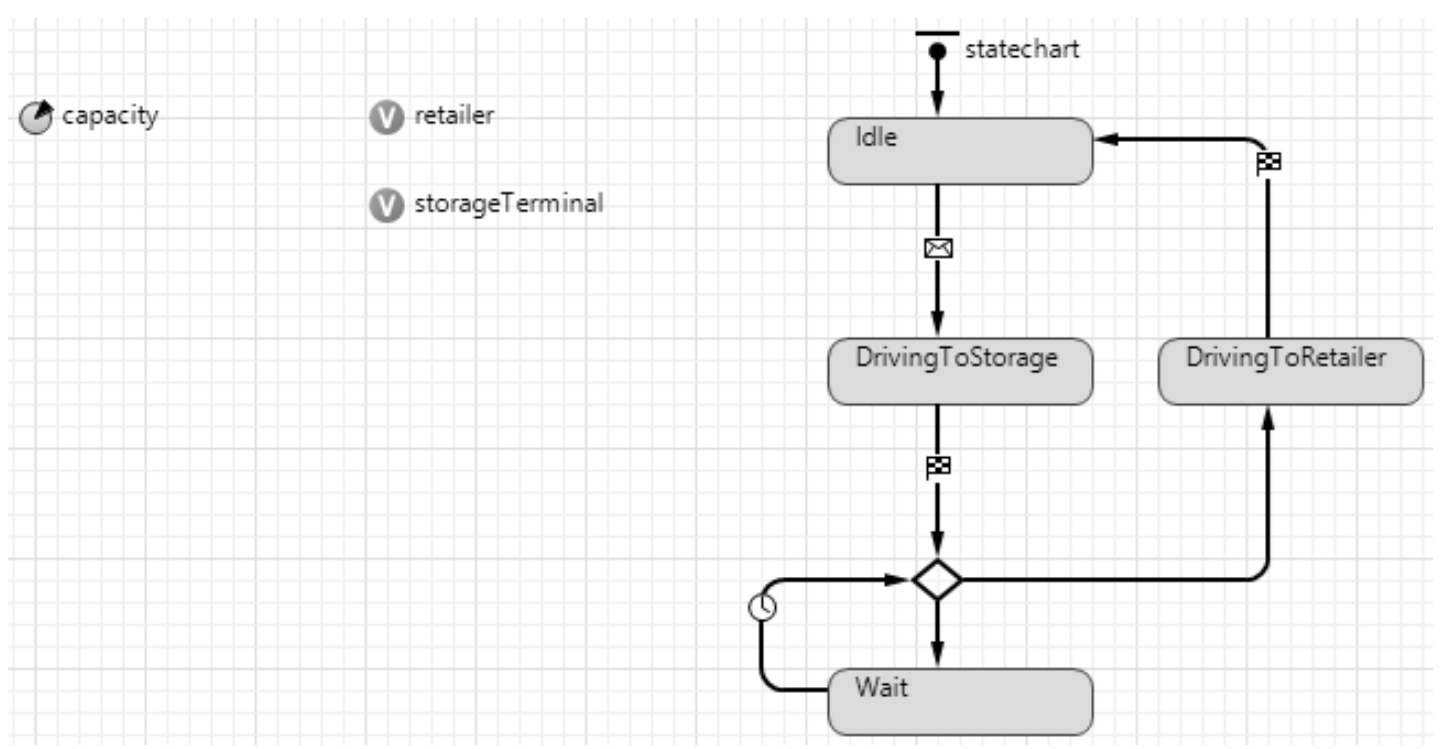

Рис. 6. Блок-схема модели агента Бензовоз (FuelTruck)

- Агент Узлов Нефтепровода для транспортировки сырой нефти и нефтепродуктов $\mathbb{*}$, PipelineNode, который состоит из двух параметров-переменных (см. РисуHOK 5):

- Емкость , сарасіty, Начальное значение: 5 000:

- Местонахождение , location, а также агент Узлов Нефтепровода состоит их одной переменной:

- Запас (есть в наличии) Q, stock, Начальное значение: uniform(capacity/2, capacity); а также агент Узлов Нефтепровода состоит из пяти функции:

- Добавить $\Theta$, add, которая определяет действие: if(stock + amount > capacity) error("Overflow: trying to add above capacity"); stock+=amount;

- Вход в емкость $\Theta$, inputCapacity, которая возвращает значение: Capacity;

- Вход в запас $\boldsymbol{E}$, inputStock, которая возвращает значение: stock;

- Выход из запаса $\Theta$, outputStock, которая возвращает значение: stock;
- Удалить $\mathrm{E}$, remove, действие: if(stock - amount <0) error("Trying to remove more than available"); stock-=amount;

- Агент Бензовоз для транспортировки нефтепродуктов $\mathbf{A}$, FuelTruck, который состоит из одного параметра-переменной (см. Рисунок 6):

- Емкость (- capacity, Начальное значение: 10, а также агент Бензовоз состоит их двух переменной:

- Ритейлер (V, retailer, Начальное значение: main.retailers.get(getIndex());

- Терминал для хранения нефтепродуктов (v, storageTerminal, а также агент Бензовоз состоит из одного Диаграммы состояния [5].

Здесь отметим, что если у агента можно выделить несколько состояний, выполняющих различные действия при происхождении каких-то событий, или если 


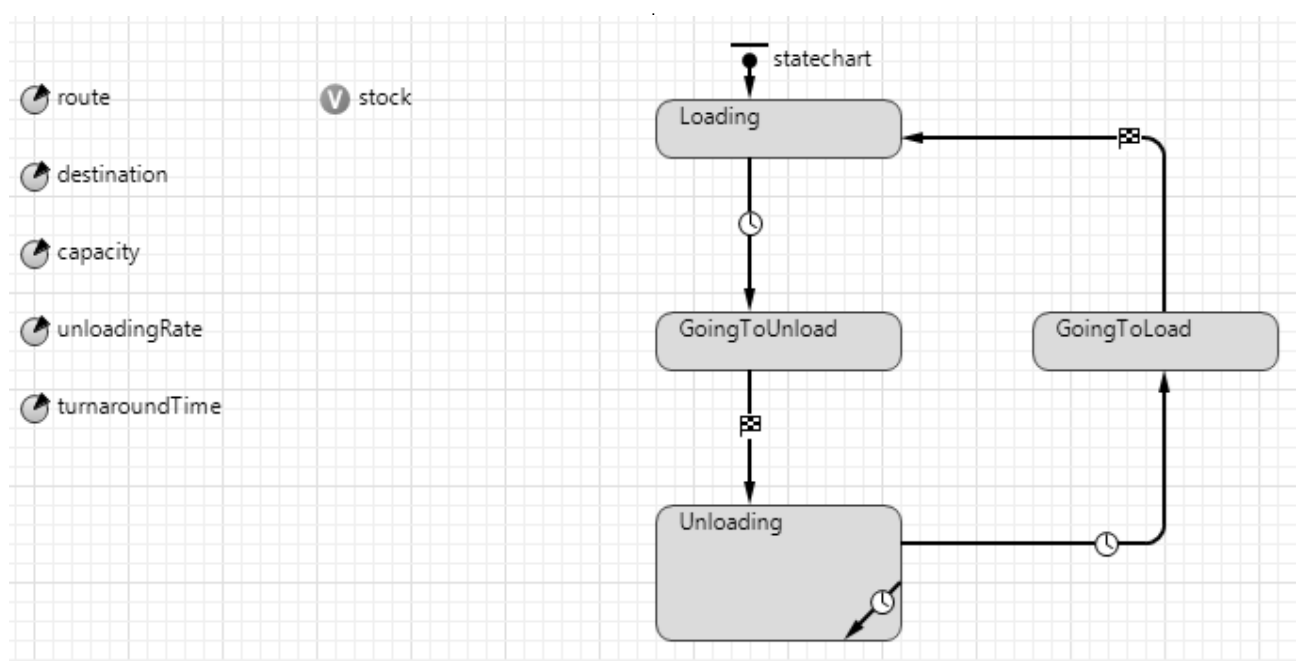

Рис. 7. Блок-схема модели агента Танкера (Tanker)

у агента есть несколько качественно различных поведений, последовательно сменяющих друг друга при происхождении определенных событий, то поведение такого объекта может быть описано в терминах диаграммы состояний. С помощью диаграмм состояний можно графически задать дискретные поведения объектов любой сложности, куда более разнообразные, чем элементарные состояния свободен/занят (idle/ busy), открыт/закрыт (open/closed), исправен/неисправен (up/down) и т.п., предлагаемые большинством блочных инструментов моделирования [2-9].

Диаграмма состояний представляет собой состояния, соединенные переходами. Переходы могут сработать в результате заданного в качестве условия перехода события - это может быть истечение заданного таймаута, получение диаграммой состояний сообщения, выполнение заданного логического условия и т.д. Срабатывание перехода приводит к переходу управления диаграммы состояний в то состояние, в которое ведет этот переход. Состояния могут быть иерархическими, т.е. содержать другие состояния и переходы.

Таким образом, Диаграмма состояния которая состоит из:

- Начало диаграммы состояний /, statechart,

- Состояние Холостой ход $\bigcirc$, Idle,

- Состояние Движение к хранилищу DrivingToStorage,

- Состояние Движение к ритейлер $\bigcirc$, DrivingToRetailer,

- Состояние Ожидание $\bigcirc$, Wait,

- Ветвление $\diamond$, branch,

- Переход transition; Действие: storageTerminal = msg;
moveTo(storageTerminal.getX() + uniform $(-3,3)$, storageTerminal.get $Y()+$ uniform $(-3,3))$;

- Переход 4 transition1, Происходит: По прибытию агента.

- Переход (transition2, Происходит: По прибытию агента. Действие:

retailer.add(capacity);

if(retailer.stock<retailer.orderUpTo)

send(retailer.storageTerminal, this);

- Переход 4 , transition3, Условие: storageTerminal. outputStock() >= capacity;

Действие: storageTerminal.remove(capacity); storageTerminal = null;

moveTo(retailer.getX ()$+$ uniform $(-3,3)$, retailer.getY ()$+$ uniform $(-3,3))$;

- Переход $\$$, transition4,

- Переход transition5, Происходит: Потаймауту. Таймаут: day().

- Агент Танкер для транспортировки сырой нефти А. Tanker, который состоит из пяти параметра-переменной (см. Рисунок 7):

- Емкость ( сарасіty, Начальное значение: 5 000,

- Пункт назначения для транспортировки нефтепродуктов из узлов нефтепровода, destination,

- Дорога $\mathcal{C}$, route,

- Время оборачиваемости ( ) turnaroundTime, Значение по умолчанию: 10,

- Норма разгрузки $\mathcal{G}$, unloadingRate, Значение по умолчанию: 500, а также агентаТанкера состоит из одной переменной: 
- Запас (есть в наличии) V, stock, а также агент Танкер состоит из одного:

- Диаграмма состояния 공, statechart, которая состоит из:

- Начало диаграммы состояний /, statechart,

- Состояние погрузка $\bigcirc$, Loading,

- Состояние Объем идущие выгрузки GoingToUnload,

- Состояние Разгрузка $\bigcirc$, Unloading,

- Состояние Объем идущие разгрузки $\bigcirc$, GoingToLoad,

- Переход transition; Происходит: Потаймауту. Таймаут: turnaroundTime* day(). Действие: stock = capacity; tanker.setVisible(true); moveTo(route.getNode(1));

- Переход transition1, Происходит: Поприбытию агента.

- Переход transition2, Происходит: Потаймауту. Таймаут: 10 Действие: moveTo(route.getNode(0));

- Переход transition3, Происходит: Поприбытию агента. Действие: tanker.setVisible(false);

- Переход transition4, Происходит: Потаймауту. Таймаут: day().Действие: //limit the amount with the unloading rate

double $\mathrm{a}=\min$ (stock, unloadingRate);

//further limit it with the space available in the destination storage $\mathrm{a}=\min (\mathrm{a}$, destination.inputCapacity ()$-$ destination. inputStock());

stock $-=\mathrm{a}$; destination.add(a);

Цепочки поставок являются важными для многих систем, и многие из них показывают постоянную нестабильность и колебания. Каждая цепочка поставок состоит из запасов и политики управления, используемой для их управления. Эта политика управления направлена на поддержание запасов на целевом уровне, компенсацию потерь от использования или потерь, а также непредвиденных нарушений в окружающей среде. Часто возникают значительные задержки между попыткой отслеживания и началом результата, что создает сеть доставки незаполненных заказов.

В статье представлена разработка современных математических моделей цепочки поставок сырой нефти и нефтепродуктов в Казахстане для научного обоснования характеристик деятельности агентов нефтяной отрасли страны и получены следующие результаты:

- предоставлен полный обзор ситуации нефтяной отрасли Республики Казахстан;

- проведен компьютерный эксперимент модели цепочки поставок нефти и нефтепродуктов в Республике Казахстан: Хранилище, Нефтеперерабатывающий завод, Трубопровод и Терминал нефтепродуктов;

- на основе компьтерных экспериментов были определены оценки параетров характеристик агентов цепочки поставок сырой нефти и нефтепродуктов;

\section{ЛИТЕРАТУРА}

1. Sterman J.D. Business Dynamics: Systems Thinking and Modeling for a Complex World. McGraw-Hill Inc. — 2000. p. 740.

2. Официальный сайт открытых проектов имитационного моделирования The AnyLogic Company. URL: https://www.anylogic.com

3. Орлова И.В. Экономико-математические методы и модели: компьютерное моделирование: Учебное пособие / И.В. Орлова, В.А. Половников. - М.: Вузовский учебник, 2017. - 344 с.

4. Колпаков В.Ф. Экономико-математическое и эконометрическое моделирование: Компьютерный практикум: Учебное пособие / В.Ф. Колпаков. - М.: Инфра-М, 2018. - 672 с

5. Вьюненко Л.Ф. Имитационное моделирование: Учебник и практикум для академического бакалавриата / Л.Ф. Вьюненко, М.В. Михайлов, Т.Н. Первозванская.— Люберцы: Юрайт, 2016. — 283 с 